\title{
AMBIÊNCIAS HÍBRIDAS-FORMATIVAS NA EDUCAÇÃO ONLINE: DESAFIOS E POTENCIALIDADES EM TEMPOS DE CIBERCULTURA
}

\author{
HYBRID-TRAINING ENVIROMENTS IN ONLINE LEARNING: \\ CHALLENGES AND POTENTIALITIES IN CIBERCULTURE
}

\section{AMBIENTES HÍBRIDOS-FORMATIVOS EN LA EDUCACIÓN EN LÍNEA: DESAFÍOS Y POTENCIAS EN TIEMPOS DE CIBERCULTURA}

\author{
Mayra Rodrigues Fernandes Ribeiro ${ }^{1}$ \\ Felipe da Silva Ponte de Carvalho ${ }^{2}$ \\ Rosemary dos Santos ${ }^{3}$
}

RESUMO: Este artigo, de cunho teórico, problematiza as noções de educação online (EOL), desenho didático em ambiências híbridas-formativas, formação, autoria e docência, a partir da cena sóciotécnica emergente, que denominamos de cibercultura. Apostamos na EOL como um dos fenômenos da cultura contemporânea em rede, discutindo os desdobramentos de suas fases e de seus fundamentos e tencionando que ela exige metodologia própria, práticas educativas contextualizadas e docência voltada para a interatividade e colaboração. Por fim, partimos do pressuposto que o papel da docência é fundamental na EOL, ela é responsável não só pelo processo de mediação entre o objeto a ser conhecido e os/as cursistas, como também por todo o processo formativo, atuando nas problematizações em sala de aula, promovendo autorias e partilhas de experiências e na ampliação dos repertórios culturais e de conhecimentos.

PALAVRAS-CHAVE: educação online; desenho didático; ambiências híbridas-formativas; formação; autoria; e docência.

ABSTRACT: This theoretical article discusses notions of Online Learning, didactic planning in hybrid-formative environments, training, authorship and teaching, from the emerging socio-technical context we call cyberculture. We defend the Online Learning as one of the phenomena of the

Submetido em: 28/09/2017 - Aceito em: 12/11/2017 - Publicado em: 28/02/2018.

${ }^{1}$ Professora Adjunta do Departamento de Educação da UERN. Doutora em Educação em Educação ProPed/Uerj. Integrante do Grupo de Pesquisa em Docência e Cibercultura - UERJ e do Grupo de Pesquisa em Formação e Profissionalização do Professor - UERN. Professora no Programa de Pós Graduação em Educação e no Mestrado Profissional em Biologia - UERN. E-mail: mayra.rfr@ gmail.com Orcid: 0000-0002-3118-026.

${ }^{2}$ Mestre e doutorando em Educação ProPed/Uerj, pesquisador do Grupo de Pesquisa em Docência e Cibercultura (Gpdoc). Bolsista FAPERJ. E-mail: felipesilvaponte @ gmail.com Orcid: http://orcid.org/0000-0001-7398-6171

${ }^{3}$ Professora Adjunta do Departamento de Formação de Professores da Faculdade de Educação da Baixada Fluminense (FEBF-UERJ). Doutora e Mestre em Educação pela UERJ. Professora da Rede Municipal de Educação Duque de Caxias. Vice-coordenadora do GPDOC - Grupo de Pesquisa Docência e Cibercultura. Tutora de Educação a distância. Site: www.docenciaonline.pro.br. E-mail: rose.brisaerc@gmail.com

\begin{tabular}{l|l|l|l|l|l|l} 
(C) Redoc & Rio de Janeiro & v.2 & n.1 & p. 1 & Jan/Abr. 2018 & ISSN 2594-9004
\end{tabular}




\section{Revista Docência e Cibercultura}

contemporary culture in network, discussing the unfolding of its phases and its foundations and stressing that the Online Learning requires its own methodology, contextualized educational practices and teaching focused on interactivity and collaboration. Thus, we assume that the role of teaching is fundamental in the Online Learning, since it is responsible not only for the process of mediation between the object to be known and the students, but also for the whole formative process, acting in the problematizations in the classroom, promoting authorizations and exchanges of experiences and in the expansion of cultural repertoires and of knowledge.

KEYWORDS: Online Learning; didactic planning; hybrid-formative environments; training; authorship; teaching

RESUMEN: Este artículo teórico, problematiza nociones de Educación en Línea (EeL), planificación didáctica en ambientes híbridos-formativos, formación, autoria y docencia, a partir del contexto sócio-técnico emergente que denominamos cibercultura. Defendemos la EeL como uno de los fenómenos de la cultura contemporánea en red, discutiendo los desdoblamientos de sus fases y de sus fundamentos y tensionando que la EeL exige una metodología propia, prácticas educativas contextualizadas y docência volcada a la interactividad y colaboración. Así, partimos del presupuesto de que el papel de la docencia es fundamental en la EeL, ya que ES responsable no solo por el proceso de mediación entre el objeto a ser conocido y los/las cursistas, como también por todo el proceso formativo, actuando en las problematizaciones en sala de aula, promoviendo autorías e intercambios de experiencias y en la ampliación de repertórios culturales y de conocimientos.

PALABRAS CLAVE: Educación en Línea; planificación didáctica; ambientes híbridos-formativos; formación; autoria; docencia.

\section{A EDUCAÇÃO ONLINE COMO FENÔMENO DA CIBERCULTURA}

A paisagem comunicacional contemporânea é formada por fluxos de informações, onde qualquer um pode produzir, processar, armazenar e circular informação sobre vários formatos com a liberação do polo de emissão, com a conexão, a reconfiguração e a convergência das mídias digitais em rede (LEMOS \& LÉVY, 2010; CASTELLS, 2015; LUCENA, 2014; SANTAELLA; 2010).

É no ciberespaço e, especificamente, nos ambientes virtuais de aprendizagem (AVA) que saberes são produzidos, principalmente no que se refere a aprender com o outro e em conjunto, construindo uma rede de aprendizagem em um ambiente aberto, plástico, fluido, atemporal e ininterrupto.

A cibercultura, de acordo com Santos, Carvalho e Rossini (2015), se caracteriza pela mobilidade ubíqua, pervasiva ou senciente, pela conectividade com o ciberespaço e as cidades, o que provoca profundas modificações no espaço urbano, nas configurações sociais e nas práticas cotidianas. Destacamos aqui os potenciais comunicacionais e pedagógicos dos artefatos 


\section{Revista Docência e Cibercultura}

ciberculturais, principalmente porque potencializam os usos dos professores ao constituírem-se em espaços para produzir e cocriar conhecimento em rede.

Esse cenário cibercultural possibilita novos projetos curriculares, como a educação online (EOL), vêm demandando investimentos na formação de professores, nos estudos e pesquisas neste campo e investimento na infraestrutura técnica. A partir do contexto da EOL que situamos o presente trabalho, e entendemos que esta educação não separa práticas da educação presencial das práticas da educação a distância, uma vez que, como nos diz Santos e Silva (2009), estar geograficamente disperso não é estar distante, principalmente quando temos tecnologias digitais em rede.

Entre os desafios contemporâneos da educação temos uma sociedade envolvida pelas tecnologias digitais, por redes sociais, por estudantes que vivem o digital com seus dispositivos móveis, com suas páginas pessoais nas redes sociais. Por isso, um dos grandes desafios da EOL é fazer com que professores e alunos possam vivenciar situações de aprendizagem nesse novo contexto sociotécnico, cuja característica principal não está mais na mídia de massa, mas na informação digitalizada e em rede. Desse modo, defendemos uma educação que seja refletida e sistematizada sobre as experiências que professores e estudantes têm com o contexto cibercultural do nosso tempo. Uma educação que se aproprie das potencialidades comunicacionais e pedagógicas das mídias digitais e das redes sociais.

A dinâmica dos ambientes online é capaz de criar redes sociais de docência e aprendizagem, pois permite experiências significativas de aprendizagem nos diferentes espaçostempos da cibercultura. Para Santos $(2005,2010)$, a educação online não é apenas uma evolução das gerações da EAD, mas um fenômeno da cibercultura. E como fenômeno a EOL se atualiza, se reinventa a partir das experiências e dos usos dos ambientes de aprendizagem. Para melhor exemplificar essa reinvenção trazemos abaixo algumas fases da educação online:

- $\mathbf{1}^{\circ}$ fase - está voltada para a interatividade, Web Quest interativa, cocriação nas práticas educativas via meios comunicacionais como: lista e fórum de discussão, e-mail, mensageiro instantâneo, bate-papo; Moodle como ambiente de aprendizagem mais utilizado nas atividades online (SANTOS, E., 2005);

- $\mathbf{2}^{\mathbf{0}}$ fase - é marcada pela colaboração em rede por meio das redes sociais digitais (Orkut, YouTube, Twitter, Facebook), sistemas de escrita colaborativa (wikis), editores de imagens, textos, planilhas, apresentação e vídeo online (WEBER, SANTOS, R. \& 


\section{Revista Docência e Cibercultura}

SANTOS, E., 2012; SANTOS, E., \& WEBER, 2013; SANTOS, E., CARVALHO \& ROSSINI, 2015, CARVALHO \& PIMENTEL, 2016);

- $3^{\mathbf{0}}$ fase (atual) - sinaliza para a emergência dos usos dos dispositivos móveis, aplicativos (WhastApp, Instagram), realidade aumentada (Aurasma), internet das coisas e objetos inteligentes nas práticas educativas (PIMENTEL, FILIPPO \& SANTOS, T., 2015).

Essas fases da educação online nos ajudam a compreender o potencial do digital em rede atrelado as práticas educativas, práticas essas voltadas para experiências formativas e autorais que são bricoladas com múltiplas ambiências (fórum, bate-papo, produção de HQ, RA....).

\section{DESENHO DIDÁTICO DA EOL EM AMBIÊNCIAS HÍBRIDAS FORMATIVAS}

Por exigir metodologia própria, a EOL requer um desenho didático (SANTOS, E. e SILVA, 2009) hipertextutal, podendo ser composto por diversos conteúdos, por meio de conversação e de autoria, conectado com redes sociais, não existindo um padrão definido e único, devendo ser concebido de acordo com o contexto no qual a formação está situada e a formação que se objetiva. Levamos em consideração que os recursos, as concepções e as práticas pedagógicas que compõem o desenho didático são atos políticos, uma vez que, ao escolhê-los, estamos elegendo-os como formativos para um determinado ato de currículo (MACEDO, 2013).

Silva (2012) nos diz que um desenho didático em educação online precisa contemplar princípios de colaboração, troca de informações e opiniões, participação, autoria criativa e que o professor esteja em sintonia com esse desenho didático para não subutilizá-lo. A premissa apresentada por Silva (2012) inspira a elaboração de desenho didático para as práticas da docência online e é instigadora de dilemas sobre a tutoria em EAD, pois, temos observado em nossas experiências que esta última, quando inspirada em epistemologias tradicionais subutilizam a potência das interfaces de conteúdo e de práticas comunicacionais interativas e hipertextual.

As múltiplas mídias e as suas mais diversas linguagens passaram a integrar uma mesma ambiência no digital, chamada de multimídia por Santaella (2010), que é a mistura de dados resultante do tratamento digital de todas as informações (imagens, vídeo, texto, sons, gráficos, programas informáticos, entre outros). A conexão da multimídia com o hipertexto digital faz emergir a "hipermídia", que é a linguagem própria e legítima do ciberespaço, à qual é compreendida como as "hibridações das mídias mais as estruturas hiper das informações nas redes. Com isso, ganha 


\section{Revista Docência e Cibercultura}

importância na hipermídia o papel desempenhado pelo interator, sem o qual a hipermídia não se realiza" (SANTAELLA, 2010, p. 87-92).

Backes e Schlemmer (2013) argumentam que a articulação e integração de diferentes tecnologias digitais (TD) dá sentido ao "hibridismo tecnológico digital". As autoras asseveram que o hibridismo tecnológico digital consiste no "desenvolvimento de diferentes TD, principalmente no contexto da Web 2.0 e Web 3.0, o que tem contribuído para diversificar as formas de: interação, comunicação e representação do conhecimento" (BACKES; SCHLEMMER, 2013, p. 245). Para as autoras, o hibridismo das tecnologias digitais permitiu a constituição de espaços virtuais de convivência, nos quais os praticantes da cibercultura expõem suas compreensões e suas definições no viver e conviver com o outro.

Com base na conjuntura da hipermídia com o hibridismo tecnológico digital, que pensamos e propusemos as "ambiências híbridas" (CARVALHO, 2015); ou seja, hibridizamos diferentes mídias/interfaces/artefatos para compor o ambiente virtual de aprendizagem (AVA), tornando-o mais aberto para a tessitura do conhecimento em rede e com mais plasticidade para estruturar as ambiências do processo de aprendizagem-ensino.

Já Santos, R. (2015, p. 40) salienta que

Ambiências formativas são as situações de aprendizagem cocriadas nos espaçostempos híbridos em que se articulam os ambientes físicos e digitais (sala de aula presencial, ambientes virtuais de aprendizagem e redes sociais). Uma ambiência formativa é o complexo enredamento onde se dinamizam diversas possibilidades de produção intelectual, de invenção, de constituição de rastros onde um coletivo assume, explicita e reinventa seu processo de formação.

Já as "ambiências híbridas" são espaços organizacionais vivos, formativos e híbridos (presencial/online), que envolvem e tornam a sala de aula mais receptível/flexível para os estudantes, viabilizando cocriações entre professor-estudantes/estudantes-estudantes (CARVALHO, 2015). Essa noção visa possibilitar o/a aprendente a interagir, discutir com o coletivo, manipular e criar seus próprios conteúdos/artefatos, convidar o outro para dialogar e colaborar com o produto criado, além de compartilhar a (co)autoria em rede.

As ambiências híbridas estão organizadas em três pilares, levando-se em consideração: as fontes de informações (para situar a temática, prática e concepção que faz parte da aula ou atividade); os sistemas de autoria (para a manifestação de autorias nas ações de aprendizagem individual/dupla/grupo); e as redes sociais digitais (para compartilhar, discutir e tecer o 


\section{Revista Docência e Cibercultura}

conhecimento mais aberto e informal, proporcionando a tessitura dos atos de currículo para além dos espaçostempos institucional).

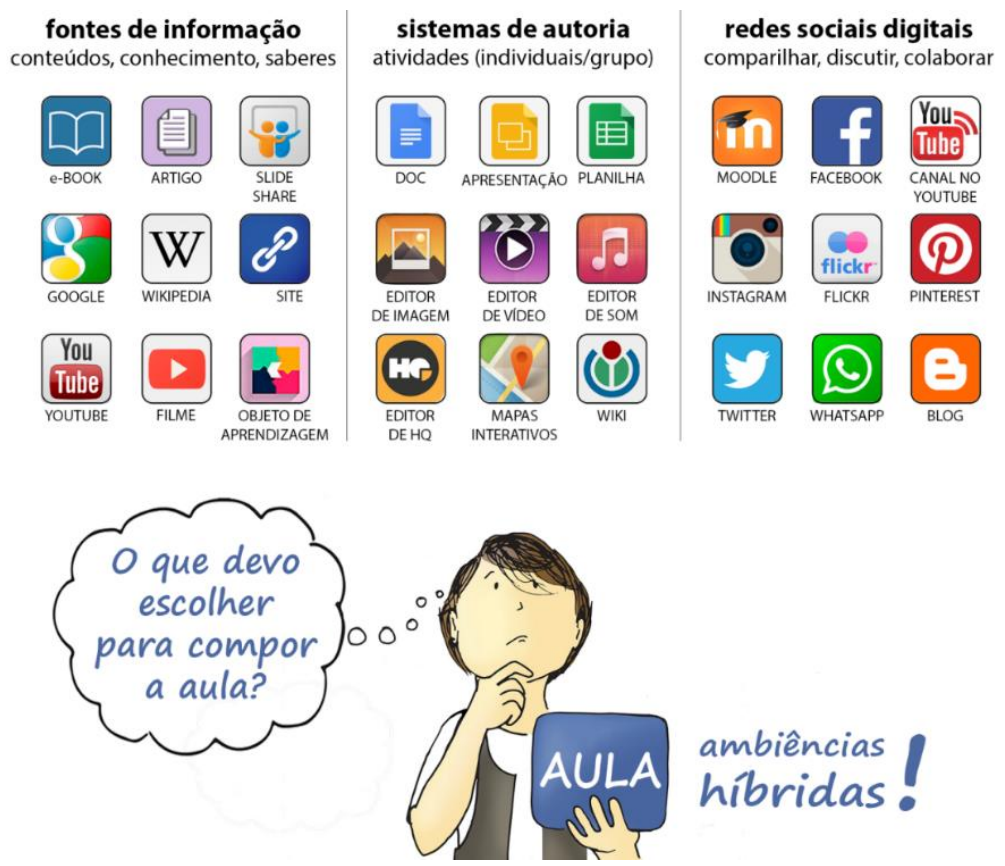

Figura 1 - Pilares da ambiência híbrida. Fonte: CARVALHO, 2015

Esses três pilares inspiram a docência à fazer-criar o seu desenho didático e seus atos de currículo, seja para oportunizar momentos de conversas que produzam a reflexão e a discussão, com a participação coletiva de todos os envolvidos, seja para convidar o aprendente à (co)autoria; isso é, para que ele (o/a aprendente) cocrie algo com os colegas, para que as ideias possam ser debatidas, confrontadas, tecidas e aprimoradas, com vistas a ir além da condição de consumidor de conteúdos, passando também a criar, disponibilizar, discutir e compartilhar suas autorias em rede.

Sendo assim, com as ambiências híbridas, buscamos promover "três manifestações de autoria”, propostas por Backes (2013), que são: pré-autoria, na qual as narrativas pós-leitura de referenciais teóricos seguem a lógica da semelhança e concordância com o texto lido, ou com o relato do colega; a autoria transformadora, na qual já se percebem posicionamentos críticos por parte dos alunos, bem como uma relação direta do conhecimento construído e os novos elementos do viver; e, finalmente, a autoria criadora, no qual o aluno se autoriza, de forma criativa, mediante certo deslocamento, uma espécie de inversão e modificação das representações, para dar passagem ao novo, promovendo, dessa forma, diferença na rede de relações estabelecida com o grupo.

\section{A FORMAÇÃO PLURAL E AUTORAL DA DOCÊNCIA ONLINE}




\section{Revista Docência e Cibercultura}

São muitos os caminhos possíveis de se pensar-fazer a formação docente e discente no contexto da cibercultura. Nesses meandros, opções político, epistemológicas e metodológicas podem nos colocar no caminho da formação massiva e alienadora ou em itinerâncias, da busca em devir, por uma cidadania autoral na cibercultura (RIBEIRO, 2015). A noção de ciberautorcidadão (RIBEIRO, 2015), entendida como formação expressa por meio de uma postura autoral, crítica, multiletrada, plural, imersiva e implicada com/na cibercultura, é possível de ser instigada em espaços de aprendizagens que favoreçam a interação dos sujeitos, sobretudo por meio de artefatos técnicoculturais que potencializem aprendizagens coletivas e instigadoras de conhecimentos plurais e heterogêneos.

A docência online é espaço de pesquisa e de formação, na qual inovamos, a cada pesquisa, metodologias tecidas na prática docente junto com os praticantes da cibercultura. Com isso reafirmamos o já dito anteriormente, a docência online como fenômeno da cibercultura avança em relação a ideia de Educação a Distância que fragmenta os processos de pensar e fazer a docência e ainda se configura em um desenho didático como repositório de textos e atividades para serem respondidas em uma linearidade de propósitos.

A docência online no contexto da cibercultura viabiliza mudanças nas formas de interação, comunicação e colaboração envolvendo conteúdos midiáticos diversos em uma relação híbrida formada por "humanos e não humanos" (LATOUR, 2012), potencializando novas práticas formativas uma vez que possibilitam a organização de processos de ensino-aprendizagem mais horizontalizados e autorais.

O contexto sociotécnico emergente nos remete a novas formas de aprender-ensinar. Possibilidades plurais de criação de dispositivos ${ }^{4}$ (ARDOINO, 2003) online ampliam as formas de mediação em espaçostempos de aprendizagens colaborativas e interativas. Remetemos-nos a Paulo Freire (1998) para ressaltarmos que em toda ação pedagógica existem epistemologias que não são neutras, mas ideologicamente determinadas, ou seja, toda ação pedagógica exercida por um professor tem intencionalidades, às vezes consciente, às vezes inócua. Frente a isso, se faz necessário a superação da ingenuidade para dar lugar à curiosidade epistemológica, com maior rigor metodológico.

\footnotetext{
${ }^{4}$ Dispositivo, para Ardoino (2003, p. 80), é a "organização de meios materiais e/ou intelectuais, fazendo parte de uma estratégia de conhecimento de um objeto".
} 


\section{Revista Docência e Cibercultura}

Em tempos de cibercultura, as mensagens não são mais produzidas sob a centralidade do emissor, cada vez mais se diversifica pelos interagentes nas redes midiáticas, o que mostra as vantagens das capacidades interativas (CASTELLS apud SANTOS, E. 2014). Com essa assertiva, pensamos que o professor situado na condição de transmissor de conhecimentos definidos a priori e ensinados linearmente, precisa rever sua perspectiva metodológica e epistemológica em função das demandas formativas dos praticantes ciberculturais. Entendemos como praticantes ciberculturais os sujeitos que atuam como produtores de cultura, de saberes e de conhecimentos na relação cidadeciberespaço, ou seja, alunos e professores que protagonizam na cultura digital em rede.

Em nossas experiências formativas na docência online, seja em ambientes virtuais de aprendizagens - AVA/Moodle, ou em redes sociais como Facebook e WhatsApp, optamos pela criação de dispositivos que possibilitem aos estudantes sentirem, perceberem e viverem um aprender-ensinar inspirado em uma perspectiva de tessitura de conhecimento na qual todos colaboram, interagem, medeiam, sugerem, se autorizam. Certamente que essa opção precisa ser percebida como processo de ressignificação nas formas de participação da/na formação. Pois, nos pensamentos de Barbosa (1998), a escola tradicional está habituada a uma prática pedagógica desautorizante, que tem negado, desde os primeiros anos de escolarização, o direito do aluno de pensar, sentir, imaginar, decidir, agir. Dessa forma, nós, professores e alunos, precisamos gradativamente criar ambiências para a tessitura do conhecimento em rede, a qual todos, interativamente, colaboram, se autorizam e fortalecem a autonomia nos contextos plurais dos quais fazemos parte cotidianamente.

Alves (2010, p. 56), ao teorizar sobre as redes educativas que formam os profissionais da educação, apresenta os contextos de formação, a saber: "das práticasteorias da formação acadêmica; pedagógicas cotidianas; das políticas de governo; dos movimentos sociais; das pesquisas; das práticasteorias de produção e "usos" das mídias; vivenciadas nas cidades, nos campos ou à beira das estradas”. É na rede educativa desses contextos que se tece, sempre em processo, a formação dos profissionais da educação.

Junqueira (2010) alerta que práticas em educação à distância devem explicitar suas perspectivas pedagógicas para que os usos das interfaces digitais não se limitem ao aspecto técnico. O autor propõe uma metodologia pautada na perspectiva pedagógica sócio-interacionista fundada pelo diálogo e pela autonomia.

\section{AUTORIA NA DOCÊNCIA ONLINE}




\section{Revista Docência e Cibercultura}

Quando pensamos em ensino-aprendizagem nos deslocamos, muitas vezes, para um cenário em que o professor entra em sala de aula com seu planejamento, esquema e experiência para ensinar aos seus estudantes fundamentado em um estatuto da lógica e da razão instrumental os conceitos científicos de uma determinada área de conhecimento. Para tanto, no atual contexto de tantos artefatos técnicosculturais, lança mão de recursos audiovisuais, mais comum o projetor multimídia, para transmitir os saberes aos alunos que se dispõem a uma escuta atenta. A sala de aula se torna, nos dizeres de Siqueira (2003, p. 191), "o lugar do discurso racionalista, redutor e disciplinar que se (re) afirma a partir do discurso da autoridade, esquecendo a importância da autoridade do argumento na construção do conhecimento". Ainda, segundo o autor, é uma prática que não incentiva o aluno a ter seu próprio pensamento, a construir argumentos autorais e sim, encoraja-o a pensar e se orientar conforme os padrões cientificistas dos pensadores que reproduzem.

Esse modelo de formação, seja no presencial ou no online, impossibilita aos sujeitos/praticantes culturais, o desenvolvimento da capacidade de tornar-se a si mesmo seu próprio co-autor, ou seja, a fazer a diferenciação, a ter uma escuta diferenciada do outro que nos habita, que está em nós. A autoria é, na perspectiva que dialogamos, um encontro com a diferenciação de si e dos outros. Só seremos alguém se conseguirmos dialogar com esses outros que estão dentro de nós.

Nesse sentido, autoria é para nós uma noção fundante e cara de todo processo formativo, seja na educação presencial, online, na vida. Desenvolver essa escuta sofisticada de uma formação que se pretende autoral requer lançar mão de dispositivos que favoreçam o diálogo plural, a escuta de si, a reflexão e a reflexividade, ou seja, a primeira mais próxima do plano da razão e a segunda como a capacidade de pensar o próprio pensamento. Questionamos a fragmentação nos desenhos didáticos das práticas em EAD, nos quais muitos atores participam com papéis estanques e isolados da totalidade formativa. Essas premissas já nos afastam de uma perspectiva de Educação a Distância de inspiração cartesiana em que se disponibiliza materiais didáticos com a roupagem do hibridismo de linguagens que convergem o sonoro, o virtual e o verbal, em uma linearidade de ações para serem executadas pelos/as estudantes em um padrão que muito mais homogeneíza que ressalta as diferenças e pluralidades de pensamento. Uma formação que não dar lugar à alteridade e nem tão pouco à condição de alterar-se junto com os outros.

Em Barbosa e Almeida (2009), encontramos uma noção rara de pensar a Educação a Distância, uma distância espacial mediada por tecnologias, a qual só tem sentido se percebida como um processo formativo e educativo que se dá com o estabelecimento de uma comunicação plural e da 


\section{Revista Docência e Cibercultura}

ordem do heterogêneo, com o outro. Assim, o uso de interfaces de comunicação e de conteúdos que proporcionem aos alunos um espaçotempo de se colocar, negatricizar ${ }^{5}$ e exercitar sua (co)autoria diante dessas práticas é, para nós, o sentido da formação autoral e autorizante na cibercultura.

Silva (2005), ao discutir sala de aula interativa na modalidade online, ou seja, a articulação da emissão e da recepção na co-criação da mensagem, nos diz da feliz coincidência histórica de vivermos a época da cibercultura com toda a sua potência favorável ao desenvolvimento da autoria, compartilhamento, conectividade, interação social e colaboração. A aula interativa discutida pelo autor vai ao encontro de ideias de grandes pensadores da educação no século XX, como Paulo Freire, Freinet, Vigotski, Anísio Teixeira, que já defendiam, em outros contextos, uma educação fundada nos princípios da autonomia, da diversidade, da interação e da dialogicidade.

Apresentamos a Figura 2 abaixo para enfatizarmos as epistemologias que inspiram práticas docentes distanciadas da liberação dos polos da emissão e da recepção e da colaboração e interatividade. Assim temos na apresentação de Silva (2017) a seguinte demonstração: a figura 1, expressando a enunciação de conteúdos, seja em texto escrito ou vídeo para serem respondidos, separadamente, pelos receptores/cursistas passivos das/nas atividades e ou questionamentos, modelo conhecido por todos como tradicional. Na figura 2, observa-se um avanço em relação ao modelo anterior, com uma tentativa de proporcionar uma conversa entre os cursistas, mas sem sair do enquadramento da enunciação. Na figura 3, nossa busca em devir, uma formação colaborativa, na qual todos-todos interagem em uma aprendizagem colaborativa e interativa, com liberação dos polos da emissão e da recepção.

\footnotetext{
${ }^{5}$ A negatricidade (ARDOINO, 1998), noção da cibercultura, está em nossas redes com a capacidade que temos de "desjogar o jogo do outro", de sermos surpreendidos diante às nossas expectativas. Essa condição, apesar de "dolorosa", nos faz avançar na alteridade e na alteração.
} 


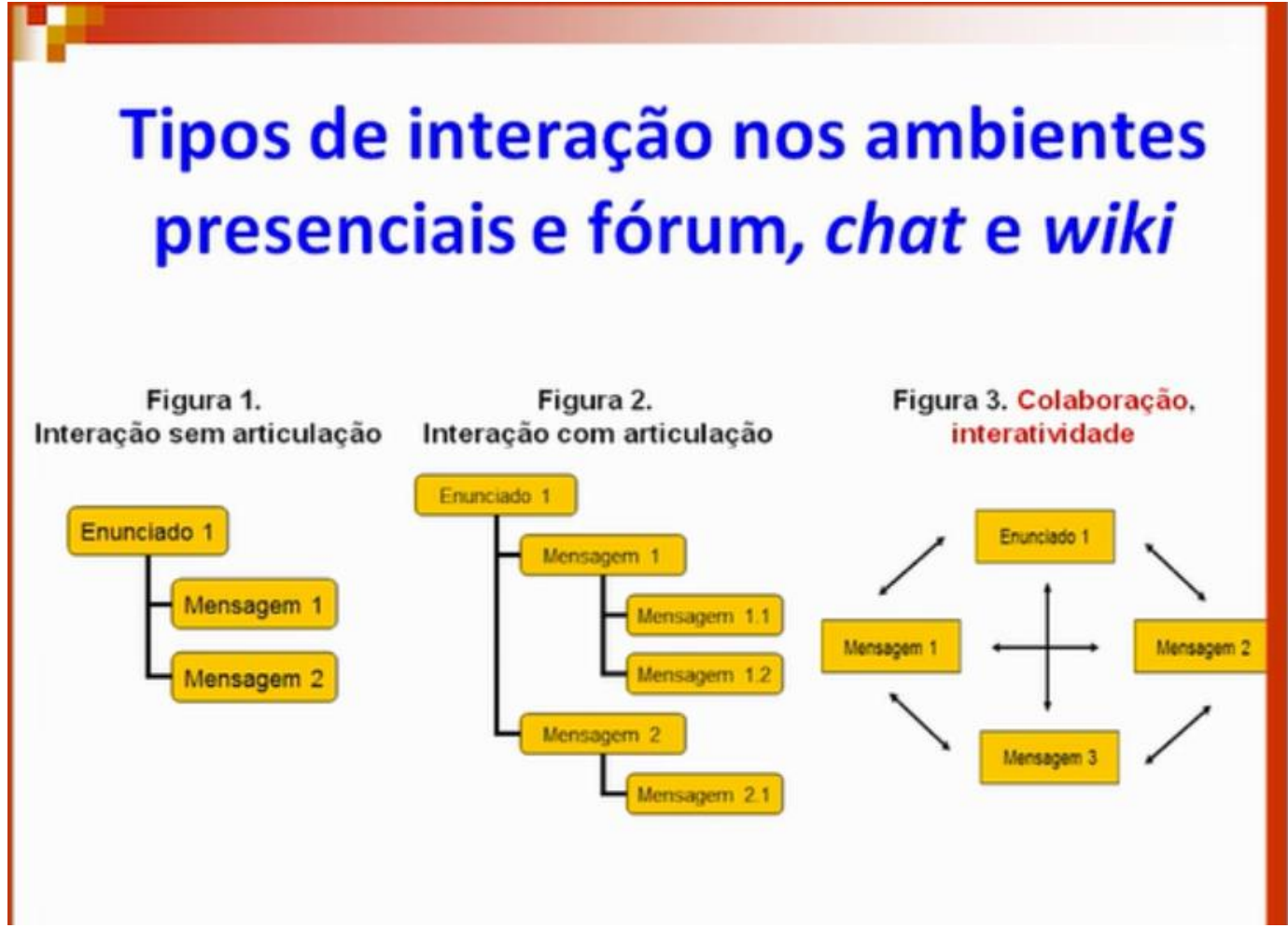

Figura 2 - Discussão dos tipos de Interatividade no presencial e online. Fonte: Vídeo Sala de Aula Interativa (2017). Disponível em: < Fonte: https://www.youtube.com/watch?v=vds722-R_74\&feature=youtu.be>

Criar, interagir, participar, autorizar-se em uma formação para/no exercício da autonomia, tem sido nossa inspiração dos/nos processos formativos da docência online e das pesquisas que tecemos junto com os praticantes culturais na cibercultura. Na educação online não tem lugar para a fragmentação de quem pensa e realiza o desenho didático. O tutor, para nós professor, é alguém implicado com todas as inseparáveis "etapas” da formação online, ou seja, a inspiração epistemológica do processo de ensino-aprendizagem, o desenho didático, a mediação, a autoria, a avaliação, etc, compõe um todo de um processo formativo.

\section{BREVES CONSIDERAÇÕES FINAIS}

Neste artigo, tencionamos as potencialidades e os desafios da educação online e seus desdobramentos para o processo formativo, o uso de meios comunicacionais e artefatos culturais em rede na prática educativa, e o papel da docência voltada para a interatividade e autoria.

Pensarfazer educação online requer participação ativa de todos os envolvidos no processo formativo, prática educativa arquitetada em sintonia com as práticas ciberculturais, requer que o docente esteja aberto ao outro, articular a interlocução de todos com todos, trazer diferentes fontes de referências e de linguagens e lançar mão de múltiplos meios para potencializar a aprendizagem. 


\section{Revista Docência e Cibercultura}

O presente trabalho, por fim, é um convite à docência em tempos de cibercultura e suas novas possibilidades pedagógicas, no qual buscamos tecer discussões e trazer noções que nos ajudem a problematizar a formação na contemporaneidade.

\section{REFERÊNCIAS}

ALVES, N. Redes educativas "dentrofora" das escolas, exemplificadas pela formação de professores. In: SANTOS, Lucíola; DALBEN, Ângela; LEAL, Júlio Dinis (Orgs.). Convergências e tensões no campo da formação e do trabalho docente: currículo, ensino de Educação Física, ensino de Geografia, ensino de história, escola, família e comunidade. Belo horizonte: Autêntica, 2010.

ARDOINO, J. Abordagem multirreferencia (plural) das situações educativas e formativas. In: BARBOSA, J. (org.). Multirreferencialidade nas ciências e na educação. São Carlos: EDUFScar, 1998.

. Para uma pedagogia socialista. Brasília: PLANO editora, 2003.

BACKES, L., SCHLEMMER, E. Práticas pedagógicas na perspectiva do hibridismo tecnológico digital. Revista Diálogo Educ., Curitiba, v. 13, n. 38, p. 243-266, jan./abr. 2013. Disponível em: <http://www2.pucpr.br/reol/index.php/dialogo?dd99=pdf\&dd1=7644>. Acesso em: 05/06/2015.

BARBOSA, J. Educação para a formação de autores cidadãos. In: Barbosa, J. (org.). Multirreferencialidade nas ciências e na educação. São Carlos: EDUFScar, 1998.

BARBOSA, J.; ALMEIDA, D. O corpo, o outro e a multirrefrencialidade: uma experi encia reflexiva em EaD. In. ALONSO, Kátia M.; RODRIGUES. Rosângela S.; BARBOSA, J. Educação a distância: práticas, reflexões e cenários plurais. Cuiabá, MT: EduFMT, 2009.

CARVALHO, F. Atos de currículo na educação online. Rio de Janeiro, 2015. Disponível em: < http://proped.pro.br/teses/teses_pdf/2013_2-1195-ME.pdf>. Dissertação (Mestrado em Educação) - ProPed/Uerj. Acessado em: 01/07/2017.

CASTELLS, M. O poder da comunicação. São Paulo/Rio de Janeiro: Paz e Terra, 2015.

FREIRE, P. Pedagogia da autonomia: saberes necessários à prática educativa. São Paulo: Paz e Terra, 1998.

JUNQUEIRA, E. S. O uso do Chat em EaD: uma proposta metodológica. Instituto UFC Virtual. 2010. Disponível em: <http://www.vdl.ufc.br/solar/aula_link/lfis/semestre01/EAD/aula_021231/02_arquivos/Aula_02_como_realizar_um_chat_educativo.doc>. Acesso em 15 abr. 2014.

LATOUR, B. Reagregrando o social: uma introdução à teoria do ator-rede. Salvador: Edufba, 2012.

LEMOS, A.; LÉVY, P. O futuro da internet: em direção a uma ciberdemocracia palentária. São Paulo: Paulus, 2010.

LUCENA, S. Cultura digital e educação do século XXI. In: LUCENA, Simone (Org). Cultural digital, jogos eletrônicos e educação. Salvador: EDUFBA, 2014, p. 11-16.

MACEDO, R. Atos de currículo e Autonomia Pedagógica: o socioconstrucionismo curricular em perspectiva. Petropólis, RJ: Vozes, 2013.

PIMENTEL, M., FILIPPO, D., \& SANTOS, T. M. (2015). Projetando o futuro da educação com computação ubíqua. Educação \& Imagem (UERJ), 5, 1-4. 


\section{Revista Docência e Cibercultura}

RIBEIRO, M. A sala de aula no contexto da cibercultura: formação docente e discente em atos de currículo. 2015. 207f. Tese (Doutorado) Orientador: Edméa Oliveira dos Santos. Faculdade de Educação. Universidade do Estado do Rio de Janeiro - UERJ, Rio de Janeiro/RJ.

SANTAELLA, L. Ecologia pluralista da comunicação: conectividade, mobilidade, ubiquidade. São Paulo: Paulus, 2010 - (Comunicação). ISBN 978-85-349-3212-7.

SANTOS, E. Educação online: cibercultura e pesquisa-formação na prática docente. Salvador. 2005. Tese (Doutorado em Educação) - FACED-UFBA.

. Educação online para além da EAD: um fenômeno da cibercultura. In. SILVA, Marco; PESCE, Lucila; ZUIN, Antônio (orgs). Educação online: cenário, formação e questões didático-metodológicas. Rio de Janeiro: wak Ed., 2010.

, WEBER, Aline. Educação e cibercultura: aprendizagem ubíqua no currículo da disciplina didática. Rev. Diálogo Educ., Curitiba, v. 13, n. 38, p. 285-303, jan./abr. 2013, Disponível em: < http://www2.pucpr.br/reol/index.php/dialogo?dd99=pdf\&dd1=7646>

. Pesquisa-formação na cibercultura. Portugal: Whitebooks, 2014.

; CARVALHO, F., ROSSINI, T. . Autoria em rede: uma prática pedagógica emergente. Revista Diálogo Educacional (PUCPR. Impresso), v. 15, p. 515-536, 2015.

; CARVALHO, F., PIMENTEL, M. Mediação docente para colaboração: notas de uma pesquisa-formação na cibercultura. Campinas, SP, Revista Educação Temática Digital (ETD), v.18, n.2, p. 23-42, jan.abr.2016. ISSN 1676-2592. Disponível em: < https://periodicos.sbu.unicamp.br/ojs/index.php/etd/article/view/8640749/12238> Acessado em: 01/07/2017

; SILVA, M. O desenho didático interativo na educação online. Revista Iberoamericana de Educación, n. 49, p. 267-287, 2009.

SANTOS, R. Formação de Formadores e Educação Superior na cibercultura: itinerâncias de Grupos de Pesquisa no Facebook. 2015. 183 f. Tese de Doutorado em Educação - Faculdade de Educação, Universidade do Estado do Rio de Janeiro, Rio de Janeiro, 2015.

SILVA, M. Docência Interativa presencial e online In: Valentini,Carla Beatris; Schelmmer, Eliane. (Org.). Aprendizagem em ambientes virtuais: compartilhando idéias e construindo cenários. Caxias do Sul: EDUCS, 2005, v. 1, p.193-202

SILVA, M. (org). Formação de professores para docência online. São Paulo: Ed. Loyola, 2012.

SILVA, M. Sala de aula interativa no presencial e no online. Universidade do Estado de Santa Catarina - UDESC, Centro de Educação a Distância - CEAD. Jan, 2017. Disponível em: https://www.youtube.com/watch?v=vds722-R_74\&feature=youtu.be

SIQUEIRA, A. O lado sensível da concretude do mundo. In: ALMEIDA, Angela Maria; KNOBB, Margarida; ALMEIDA, Maria da Conceição. Polifônicas Ideias: por uma ciência aberta. Porto Alegre: Sulina, 2003.

WEBER, A.; SANTOS, R. e SANTOS, E. Caiu na rede é peixe: o currículo no contexto das redes sociais. Revista Conhecimento \& Diversidade, Niterói, n. 8, p. 56-75 jul./dez. 2012 Disponível em:

http://www.revistas.unilasalle.edu.br/index.php/conhecimento_diversidade/article/viewFile/9 72/775> 